\title{
Fundamental Philosophy of Health and Medical Care would be
}

\section{Hinoharaism}

Bando $\mathrm{H}^{1^{*}}$

${ }^{1}$ Tokushima University / Medical Research, Tokushima, Japan

Corresponding Author: Hiroshi Bando, MD, PhD, FACP

Address: Tokushima University / Medical Research, Nakashowa 1-61, Tokushima 770-0943, Japan; Ph: +81-90-31872485; Email: pianomed@bronze.ocn.ne.jp

Received date: 06 October 2019; Accepted date: 15 October 2019; Published date: 20 November 2019

Citation: Bando H. Fundamental Philosophy of Health and Medical Care would be Hinoharaism. J Health Care and Research. 2019 Nov 20;1(1):1-3.

Copyright (C) 2019 Bando H. This is an open-access article distributed under the Creative Commons Attribution License, which permits unrestricted use, distribution, and reproduction in any medium provided the original work is properly cited.

\section{Keywords}

Health and Medical care; William Osler; Shigeaki Hinohara; Hinohara-ism; New Elderly Association (NEA); Smart Senior Association (SSA); Primary Care (PC)

Congratulations on the inaugural issue of Journal of Health Care and Research in the Asploro publishing group. In the fields of health and medical care across the world, there have been various clinical practices and research for long time. This journal would be expected to play an important role in further development in the future.

Concerning the fundamental philosophy of medicine, there were some important quotes. The words of Ambroise Paré (1510 1590) have been wellknown, which is "To cure sometimes. To relieve often. To comfort always" [1]. Furthermore, Sir William Osler (1849-1919), a Professor of Medicine at Johns Hopkins School of Medicine, had said many significant comments $[2,3]$. Among them, the following are known: "Listen to your patient; he is telling you the diagnosis", and "Medicine is a science of uncertainty and an art of probability".

Detail achievement and history of Dr. Osler was investigated by a prominent Japanese physician, Dr. Hinohara Shigeaki, who lived up to 105 years [4]. He had been respected by people for his great contribution to medical society in Japan for long. Dr. Hinohara had developed medicine and taught many doctors and medical staff about "Medicine is an art based on science" [5].

For medicine, there are two aspects of science vs art. The differences are observed between them, such as physical vs mental, body vs soul, disease vs patient, it vs you, general vs private, cure vs care, effect vs skill, rule vs disparity, evidence-based vs narrativebased, length of life vs quality of life, and so on. These factors showed transition or fusion for a long history [5]. From scientific point of view, we collect a variety of information. After that, it is essential to evaluate how to use and integrate much data from the art of implication.

Dr. Hinohara had changed medical history by teaching a variety of people associated with his own fundamental philosophy of Hinohara-ism [6]. Formerly, he introduced primary care medicine and problem-oriented system (POS) from the United 
States and showed the future direction of medicine and nursing for doctors and medical staffs as patientoriented medicine. In addition, he developed the general concept of self-care such as self-blood pressure measurement with their own health management [7]. Subsequently, in the late 1970s, he advocated lifestyle-related diseases. More than 10 years later, the Japanese Ministry of Health and Welfare decided to use lifestyle-related diseases as the recognition of increasing importance of noncommunicable disease (NCD).

Furthermore, Hinohara established the New Elderly Association (NEA) in 2000 [8]. This is a social movement aimed at the fulfilling mental, physical health of the elderly living in the 21st century. The purpose of the philosophy of NEA is as follows [9]. There is one mission, which is to transmit the importance of peace and love to children. There are three themes, including love, to initiate and to endure.

There are five goals [8], which are i) to acquire a favorable lifestyle, ii) to maintain an active role in society and close friendships regardless of gender, race, or generation, iii) to maintain hope and faith, cultivate the strength and power to endure any difficulty that one might encounter, maintain and indomitable spirit which should encompass a deep sympathy for others in difficult situations, and extend comfort to people who have lost hope in life, iv) to provide loving care for others and feel gratitude for daily life, v) to be aware that it is never too late to initiate or create something, regardless of age [10].

NEA has developed Smart Senior Association (SSA), in which members can continue mutual communication freely using facebook [5]. Dr. Hinohara started using facebook at the age of 100 . The activity of SSA has been evaluated to be superb, and then become an official partnership association by Facebook [11]. Consequently, SSA has recognized an exemplary organization that will be a model for senior communication society in Japan and also in the world for 21 century.

From the research point of view, NEA has continued various researches in the anti-aging perspective. They include hypertension, exercise, health promotion, and others [12,13]. Further, a prospective 5-year cohort study of lifestyle of the elderly was performed by 407 NEA members [13, 14]. As a result, there was evidence to predict frailty in the elderly [15-17].

As long history worldwide indicates supreme physician is versed in not only medicine but also music and cultural activities. Dr. Hinohara was also proficient musician, composer, and entertainer. $\mathrm{He}$ composed music of nocturne, and also wrote down the scenario of musical stage for children. The original book was the Fall of Freddie the leaf: a story of life for all ages by Buscaglia [18]. The musical stage was performed in Carnegie Hall in New York. Such performance and presentation had given lots of people dream and satisfactory lives with ideal heart for mutual friendship and peace.

In the fields of music, culture, literature, and art, Dr. Hinohara has also introduced music therapy into Japan and was given the Order of Culture [19]. He developed this to Japan Biomusic Association (JBA) and Japan Music Therapy Association (JMTA) for several decades. Then, he has been called the Father of Music Therapy in Japan. The author has become the chairman of annual assembly of JBA and JMTA and developed music therapy in Japan with Dr. Hinohara. Nowadays, many registered music therapists (rMTs) have taken care of the elderly and patients with dementia, mild cognitive impairment (MCI), psychiatric diseases, some disabilities, and others.

The essence of Hinohara-ism would be related to the concept of primary care (PC) medicine. PC and family medicine (FM) have been advocated and developed since the $1960 \mathrm{~s}$ in United States. Concerning the characteristics of PC, ACCCC proposed by Saultz is known, including Access to care, Comprehensive care, Coordination of care, Continuity of care, Contextual care [20]. As PC medicine has developed for half-century in Japan, the author became the chairman of the annual congress of Japan Primary Care Association (JPCA) in 2017 with 4500 attendance [21]. There was a congratulatory address 
by Hinohara on the first page of the program, in which he was satisfied with the current status of PC in Japan. It was his last official message at the age of 105, who was respected as the Father of primary care medicine in Japan.

In summary, Sir William Osler and Dr.Shigeaki Hinohara have contributed much to the development of medical and health care. We have to recognize them and endeavor further happiness of patients with various health problems in the light of Hinohara-ism.

\section{References}

[1] Dunn PM. Ambroise Paré (1510-1590): surgeon and obstetrician of the Renaissance. Arch Dis Child Fetal Neonatal Ed. 1994 Nov;71(3):F231-32. [PMID: 7820725]

[2] Osler SW. On the educational value of the medical society. 1904:343-62.

[3] Seeman MV, Becker RE. Osler and the way we were taught. Medical Science Educator. 2017 Sep 1;27(3):555-57.

[4] Hinohara S. Sir William Osler's philosophy on death. Ann Intern Med. 1993 Apr 15;118(8):638-42. [PMID: 8452331]

[5] Bando H, Yoshioka A, Iwashimizu Y, Iwashita M, Doba N. Development of Primary Care, Lifestyle Disease and New Elderly Association (NEA) in JapanCommon Philosophy With Hinohara-ism. Prim Health Care. 2017 Sep 28;7(3):281.

[6] Stafford N. Shigeaki Hinohara. BMJ. 2017;358:j3891.

[7] Hinohara S. Facing Death the Japanese WayCustoms and Ethos. InJapanese and Western Bioethics 1997 (pp. 145-154). Springer, Dordrecht.

[8] Doba N, Hinohara S, Yanai H, Saiki K, Takagi H, Tsuruwaka M, Hirano M, Matsubara H. The new elder citizen movement in Japan. Faces of Aging: The Lived Experiences of the Elderly in Japan. Matsumoto Y, Ed. Stanford University Press, Stanford. 2011 Mar 17:3659 .

[9] New Elderly Association. https://www.shinrojin.com/

[10] Bando H, Ed. Hinohara S. Let's start for significant life with New Elderly Association. Medical
Research Books. Tokushima, Japan. 2011.

[11] Bando H. Medical Practice and Research in Primary Care with Hinohara-ism. J Gen Med Prim Care. 2018;2(1):100009.

[12] Tomiyama H, Hashimoto H, Matsumoto C, Odaira M, Yoshida M, Shiina K, Nagata M, Yamashina A, Doba $\mathrm{N}$, Hinohara S. Effects of aging and persistent prehypertension on arterial stiffening. Atherosclerosis. 2011 Jul;217(1):130-34. [PMID: 21501841]

[13] Hinohara S, Doba N. The future profile of health promotion and disease prevention in Japan: based on the study of seniors over age 75 . Methods Inf Med. 2005;44(2):342-47. [PMID: 15924204]

[14] Matsubara Y, Hirano M, Doba N, Hinohara S. Life-habits and health status of active Japanese senior citizen: a structured self-check questionnaire study with a special reference to the progress of frailty. Okinawa Wellness Longevity Journal. 2008;2008:1-4. [15] Doba N, Tokuda Y, Goldstein NE, Kushiro T, Hinohara S. A pilot trial to predict frailty syndrome: the Japanese Health Research Volunteer Study. Exp Gerontol. 2012 Aug;47(8):638-43. [PMID: 22664579] [16] Yanai H, Doba N, Saiki K, Takagi H, Nishiyama E, Hinohara S. An analysis of aging effects on life habits of Japanese people. Statistics and Development Issue. Majumder A, Pal M, Ghosh B, et al, Eds. Mittal Publications, New Delhi. 2012:41-97.

[17] Doba N, Tokuda Y, Saiki K, Kushiro T, Hirano M, Matsubara Y, Hinohara S. Assessment of Self-Efficacy and its Relationship with Frailty in the Elderly. Intern Med. 2016;55(19):2785-92. [PMID: 27725537]

[18] Buscaglia LF, Buscaglia LF. The fall of Freddie the leaf: A story of life for all ages. Thorofare, NJ: Slack; 1982 Jan.

[19] Miller P. Dr Shigeaki Hinohara receives the Order of Culture. The Osler Library Newsletter. 2006;105:7. [20] Saultz JW, editor. Textbook of family medicine: defining and examining the discipline. McGraw-Hill; 2000;830.

[21] Japanese Primary Care Association (JPCA). 8th annual Congress in Shikoku Island. 2017.

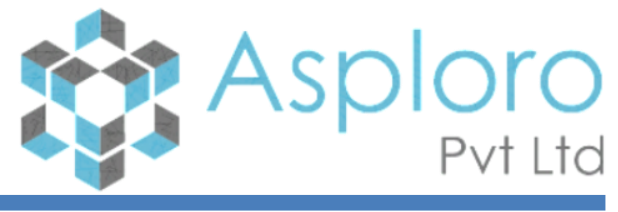

Keywords: Health and Medical care; William Osler; Shigeaki Hinohara; Hinohara-ism; New Elderly Association (NEA); Smart Senior Association (SSA); Primary Care (PC) 